\title{
TRIAGEM DE POTENCIALIDADES BIOTECNÓLOGICAS DE BACTÉRIAS ENDOFÍTICAS ISOLADAS DE FOLHAS Gossypium hirsutum L.
}

Ariana Alves Rodrigues ${ }^{1}$; Bruno Francesco Rodrigues de Oliveira ${ }^{2}$; Renan de Souza Soares $^{3}$; Luann Guilherme Vieira dos Reis ${ }^{4}$; José Daniel Gonçalves Vieira ${ }^{5}$

1 Mestre em Medicina Tropical (Microbiologia), Universidade Federal de Goiás, Goiás-Brasil (ariana.biomed@gmail.com)

2 Doutorando em Ciências (Microbiologia), Universidade Federal do Rio de Janeiro,

Rio de Janeiro-Brasil

3 Mestre em Ciências Ambientais, Universidade Federal de Goiás, Goiás-Brasil

4 Mestre em Ciências Ambientais, Universidade Federal de Goiás, Goiás-Brasil

5 Professor Doutor do Instituto de Patologia Tropical e Saúde Pública da

Universidade Federal de Goiás, Goiás-Brasil

Recebido em: 02/10/2017 - Aprovado em: 21/11/2017 - Publicado em: 05/12/2017

DOI: 10.18677/EnciBio_2017B91

\begin{abstract}
RESUMO
Gossypium hirsutum L. consiste na espécie de algodão mais cultivada em todo o mundo, apresentando importante significância histórica e econômica, principalmente no continente americano. Além das típicas pragas que afetam amplamente o algodoeiro, sabe-se que a planta exibe uma diversa comunidade microbiana simbiótica. Micro-organismos endofíticos são definidos como aqueles que passam parte ou todo o período de vida colonizando assintomaticamente tecidos vegetais e, por vários mecanismos, podem promover o crescimento do hospedeiro e participar de sua proteção frente à patógenos. $\mathrm{O}$ objetivo do atual estudo foi o isolamento $\mathrm{e}$ avaliação qualitativa de diversas potencialidades biotecnológicas de bactérias endofíticas isoladas de folha de algodão. Nove morfotipos bacterianos foram isolados, com $77,7 \%$ exibindo positividade para pelo menos um dos testes de triagem. O mesmo percentual de isolados $(77,7 \%)$ foi capaz de gerar ácido-indolacético (AIA), $66,6 \%$ solubilizaram fosfato e $55,5 \%$ cresceram em meio livre de nitrogênio. Dois isolados, AL1 e AL8, geraram exoenzimas extracelularmente e apenas um morfotipo, AL1, foi hábil em inibir o crescimento de uma das cepaspadrão bacterianas empregadas como indicadoras. Os resultados são promissores para a condução de estudos futuros que consolidaram essas possíveis aplicações das bactérias endofíticas de algodão sobre as mais diversas áreas no campo biotecnológico.
\end{abstract}

PALAVRAS-CHAVE: algodão, bactérias endofíticas, bioprospecção. 


\title{
SCREENING OF BIOTECHNOLOGICAL POTENCIALITIES OF ENDOPHYTIC BACTERIA ISOLATED FROM Gossypium hirsutum L. LEAVES
}

\begin{abstract}
Gossypium hirsutum L. consists in the most cultivated cotton species worldwide, exhibiting significative historical and economical importance, mainly in the American continent. Beyond common plagues that widely affect cotton, it is known that the plant exhibits a diverse symbiotic microbial community. Endophytic microorganisms are defined as those that spend part or the entire life period colonizing asymptotically plant tissues and, by several mechanisms, can promote the host growth and participate in its protection against pathogens. The aim of the actual work was the isolation and qualitative evaluation of various biotechnological potentialities of endophytic bacteria isolates from cotton leaves. Nine bacterial morphotypes were isolated, with $77,7 \%$ exhibiting positivity for at least one of the screening tests. The same percentage of isolates $(77,7 \%)$ was capable to produce indole-acetic-acid (IAA), 66,6\% solubilized phosphate and $55,5 \%$ grew in a free-nitrogen medium. Two isolates, AL1 and AL8, generated extracellularly exoenzymes and only one morphotype, AL1, was able to inhibit the growth of one of the applied bacterial standard strains. The results are promising for the conduction of future studies that will consolidate these possible applications of the endophytic bacteria from cotton under the most different areas in the biotechnological field.
\end{abstract}

KEYWORDS: bioprospecting, cotton, endophytic bacteria.

\section{INTRODUÇÃO}

O algodão (Gossypium hirsutum L.) é uma das culturas mais importantes e antigas do mundo, sendo o Brasil o quinto maior produtor desse cultivo. O vegetal, pertencente à família Malvaceae, destina-se primariamente a produção de fibra têxtil e óleo. Além dos produtos primários, o algodão é base para uma série de aplicações que vão desde a utilização do vegetal na medicina tradicional até alimentação do gado (CIANCHETTA; DAVIS, 2015; WEGIER et al., 2016).

A espécie tem sido alvo de estudos por diversas áreas tradicionais como as ciências agrárias, botânica, evolução e também por novas áreas, como a microbiologia, que visa compreender as relações entre os micro-organismos e o algodoeiro (WENDEL et al., 2010). Os vegetais normalmente coexistem com os micro-organismos, sendo considerados microecossistemas complexos, nos quais diferentes nichos ecológicos podem ser explorados seja por micro-organismos epifíticos, seja por endofíticos (COSTA et al., 2010). Micro-organismos endofíticos constituem um grupo formado por fungos e bactérias que vivem ou possuem parte do ciclo de vida em tecidos vegetais de forma assintomática ao hospedeiro (LOPEZ; SWORD, 2015). São conhecidos há mais de 120 anos, evidenciados como produtores de biomoléculas ativas, além de fonte produtora de compostos ainda não caracterizados (HARDOIM et al., 2008; MUNJAL et al., 2016).

Estes micro-organismos desempenham várias funções importantes para seus hospedeiros, pois realizam interações simbióticas com os mesmos e são capazes de proteger as plantas do ataque de insetos, de doenças e do ataque de mamíferos herbívoros por meio da liberação de antibióticos e também toxinas (SANTOS; VARAVALHO, 2011). A maior aplicação pauta-se na promoção do crescimento vegetal, sobretudo na capacidade de solubilizar fosfato inorgânico, fixar nitrogênio na forma de amônio, induzir resistência a patógenos por meio da produção de sideróforos e fitohormônios (PEREIRA et al., 2016). 
A bioprospecção de bactérias em plantas utilizadas em finalidades médicas e agronômicas é um campo com uma ampla variedade de possíveis aplicações, seja na pesquisa por compostos antimicrobianos/citotóxicos frente à patógenos humanos e vegetais, biofertilizantes, enzimas para a área industrial e de bioprocessos (JOE et al., 2016). Diante do exposto, este estudo teve como objetivos isolar e prospectar sistematicamente in vitro bactérias endofíticas de folhas de algodão geradoras de compostos/enzimas de interesse biotecnológico.

\section{Isolamento de micro-organismos endofíticos}

\section{MATERIAL E MÉTODOS}

As folhas de Gossypium hirsutum L. foram coletadas nas adjacências do Instituto de Patologia Tropical e Saúde Pública da Universidade Federal de Goiás (16 67' 248" S; 49 24' 366" W). Foram selecionadas apenas as folhas que não apresentavam manchas ou injúrias visíveis a olho nu. As amostras vegetais foram lavadas em água corrente e sabão, secas a temperatura ambiente sobre papel absorvente e superficialmente desinfestadas.

A sequência de desinfestação das folhas foi realizada conforme descrito por Araújo et al., (2002). A eficiência do processo de desinfestação foi testada e as folhas previamente desinfestadas foram fragmentadas assepticamente em amostras de $1,0 \mathrm{~cm}^{2}$, semeadas em placas contendo ágar nutriente (AN) e incubadas a $30^{\circ} \mathrm{C}$ por 15 dias. As placas foram monitoradas diariamente, os micro-organismos isolados por esgotamento em AN e armazenados em caldo $\mathrm{BHI}$ com glicerol a $20 \%(\mathrm{v} / \mathrm{v})$ em freezer $\mathrm{a}-20^{\circ} \mathrm{C}$.

\section{Triagem do potencial de promoção de crescimento vegetal}

Produção de ácido indol-acético (AIA)

A avaliação qualitativa da produção de AIA seguiu o método colorimétrico descrito por Gordon e Weber (1951), com modificações. Alíquotas de $100 \mu \mathrm{l}$ dos isolados, previamente crescidos em caldo $\mathrm{BHI}$, foram inoculados em caldo Triptona de Soja (TSB) a $10 \%$, suplementado com L-triptofano a $5,0 \mathrm{mM}$ e incubados a $30^{\circ} \mathrm{C}$, por 24 horas, sob rotação de $130 \mathrm{rpm}$. Após o crescimento, as culturas foram centrifugadas a $10.000 \mathrm{~g}$ por 12 minutos e $100 \mu \mathrm{l}$ do sobrenadante foi transferido para uma placa de 96 poços contendo $100 \mu$ do reagente de Salkowski $(50 \mathrm{~mL}$ de ácido perclórico a $35 \%$ e $1,0 \mathrm{~mL}$ de $\mathrm{FeCl}_{3}$ a $0,5 \mathrm{M}$ ). As placas foram incubadas no escuro por 30 minutos e a presença de uma cor rosa foi indicativo de positividade.

\section{Solubilização de fosfato}

A solubilização de fosfato foi determinada a partir do cultivo dos isolados em meio NBRIP (10 g L-1 de glucose; $5,0 \mathrm{~g} \mathrm{~L}^{-1}$ de $\mathrm{Ca}_{3}\left(\mathrm{PO}_{4}\right)_{2} ; 5,0 \mathrm{~g} \mathrm{~L}^{-1}$ de $\mathrm{MgCl}_{2} .6 \mathrm{H}_{2} \mathrm{O}$; $0,2 \mathrm{~g} \mathrm{~L}^{-1}$ de KCl; $0,25 \mathrm{~g} \mathrm{~L}^{-1}$ de $\mathrm{MgSO}_{4} \cdot 7 \mathrm{H}_{2} \mathrm{O}$ ) (NAUTIYAL, 1999). Isolados previamente crescidos em caldo $\mathrm{BHI}$, foram inoculados no meio NBRIP com o auxílio de um inoculador de Steer e incubados por sete dias a $30^{\circ} \mathrm{C}$. Foram considerados solubilizadores os micro-organismos cujas colônias apresentaram um halo transparente ao seu redor. O índice de solubilização (IS) foi determinado pela razão entre o tamanho do halo e o tamanho da colônia (LIRA-CADETE et al., 2012).

Fixação de nitrogênio

A capacidade de fixação de nitrogênio foi avaliada pelo cultivo dos microorganismos em meio semissólido livre de nitrogênio adaptado de Rennie (1981) (5,0 
$\mathrm{g} \mathrm{L}^{-1}$ de manitol; $5,0 \mathrm{~g} \mathrm{~L}^{-1}$ de sacarose; $0,4 \mathrm{~g} \mathrm{~L}^{-1}$ de $\mathrm{K}_{2} \mathrm{HPO}_{4} ; 0,4 \mathrm{~g} \mathrm{~L}^{-1}$ de $\mathrm{KH}_{2} \mathrm{PO}_{4}$; $0,2 \mathrm{~g} \mathrm{~L}^{-1}$ de $\mathrm{MgSO}_{4} \cdot 7 \mathrm{H}_{2} \mathrm{O} ; 0,02 \mathrm{~g} \mathrm{~L}^{-1}$ de $\mathrm{CaCl}_{2} ; 0,002 \mathrm{~g} \mathrm{~L}^{-1}$ de $\mathrm{NaMoO}_{4} \cdot \mathrm{H}_{2} \mathrm{O} ; 0,01 \mathrm{~g} \mathrm{~L}^{-1}$ de $\mathrm{FeCl}_{3} ; 0,075 \mathrm{~g} \mathrm{~L}^{-1}$ de bromotimol e $2,3 \mathrm{~g} \mathrm{~L}^{-1}$ de ágar, $\left.\mathrm{pH} 5,7\right)$. Os isolados foram incubados a $30^{\circ} \mathrm{C}$ por sete dias e foram considerados prováveis fixadores do gás os que turvaram o meio e modificaram a cor de verde para amarelo durante cinco repiques consecutivos.

\section{Triagem da produção de enzimas extracelulares}

A avaliação qualitativa da geração de enzimas extracelulares foi realizada através da inoculação dos micro-organismos, previamente crescidos em caldo $\mathrm{BHI}$, em meios de cultura específicos para cada enzima com o auxílio do inoculador de Steer. Foi investigada: a produção de lipase, esterase, celulases e pectinases. Após incubação por 48 horas a $30^{\circ} \mathrm{C}$, foram calculados os índices enzimáticos (IE) através da razão entre o tamanho do halo e o tamanho da colônia bacteriana.

A avaliação da produção de esterases e lipases seguiu em conformidade com a metodologia proposta por Sierra (1975), utilizando o meio bactopeptona (10 g $\mathrm{L}^{-1}$ de Bacto peptona; $5 \mathrm{~g} \mathrm{~L}^{-1}$ de $\mathrm{NaCl} ; 0,1 \mathrm{~g} \mathrm{~L}^{-1}$ de $\mathrm{CaCl}_{2} . \mathrm{H}_{2} \mathrm{O} ; 18 \mathrm{~g} \mathrm{~L}^{-1}$ de ágar, $\mathrm{pH}$ $7,2)$, suplementado com $1,0 \mathrm{~mL}$ de Tween 20 , a concentração de $1,0 \%(\mathrm{v} / \mathrm{v})$, para a atividade esterásica e $1,0 \mathrm{~mL}$ de Tween 80 , a concentração de $1 \%(\mathrm{v} / \mathrm{v})$, para a atividade lipolítica. Para ambas as enzimas, a leitura positiva é indicada pela presença de halos claros ao redor das colônias.

A habilidade em degradar a pectina foi verificada pelo cultivo dos microorganismos em meio M9 $\left(6,0 \mathrm{~g} \mathrm{~L}^{-1}\right.$ de $\mathrm{Na}_{2} \mathrm{HPO}_{4} ; 3,0 \mathrm{~g} \mathrm{~L}^{-1}$ de $\mathrm{KH}_{2} \mathrm{PO}_{4} ; 0,5 \mathrm{~g} \mathrm{~L}^{-1}$ de $\mathrm{NaCl} ; 1,2 \mathrm{~g} \mathrm{~L}^{-1}$ de extrato de levedura, $4,0 \mathrm{~g} \mathrm{~L}^{-1}$ de pectina, $15 \mathrm{~g} \mathrm{~L}^{-1}$ de ágar, acrescidos de $1 \mathrm{~mL}$ de solução de $\mathrm{MgSO}_{4} .7 \mathrm{H}_{2} \mathrm{O}$ a $0,1 \mathrm{M}$ e $10 \mathrm{~mL}$ de solução de $\mathrm{CaCl}_{2}$ a 1,0 M) (CATTELAN,1999). A presença de halos após tratamento com uma solução de $\mathrm{HCl}$ evidenciou a degradação do polissacarídeo.

Para averiguação da geração de celulases, os isolados foram incubados em meio mínimo base $\left(7,0 \mathrm{~g} \mathrm{~L}^{-1}\right.$ de $\mathrm{KH}_{2} \mathrm{PO}_{4} ; 0,1 \mathrm{~g} \mathrm{~L}^{-1}$ de $\mathrm{MgSO}_{4} .7 \mathrm{H}_{2} \mathrm{O} ; 1,0 \mathrm{~g} \mathrm{~L}^{-1}$ de $\left(\mathrm{NH}_{4}\right)_{2} \mathrm{SO}_{4} ; 0,6 \mathrm{~g} \mathrm{~L}^{-1}$ de extrato de levedura e $15 \mathrm{~g} \mathrm{~L}^{-1}$ de ágar, $\mathrm{pH} 7,2$ ) suplementado com $1,0 \%(\mathrm{~m} / \mathrm{v})$ da fonte celulolítica (STAMFORD et al., 1998). Foram testadas como fontes de celulose: a celulose microcristalina, bagaço de cana e bagaço de bambu. Após a incubação, as placas foram tratadas com uma solução de lugol e a presença de halos claros ao redor das colônias foi indicativa de degradação.

\section{Triagem da atividade antimicrobiana}

A determinação da atividade antimicrobiana seguiu a metodologia descrita por Romeiro (1989), com adaptações. Os micro-organismos endofíticos, previamente crescidos em caldo $\mathrm{BHI}$, foram inoculados em placas contendo meio sólido 523 de Kado e Heskett (KADO; HESKETT, 1970) e incubados por 48 horas a $30^{\circ} \mathrm{C}$. Após o crescimento, as placas foram expostas por 30 minutos à luz ultravioleta $(\lambda=254$ $\mathrm{nm})$. O ágar foi fragmentado e tratado com água destilada esterilizada para a extração das substâncias com ação antimicrobiana. A solução aquosa resultante foi esterilizada por filtração em filtros Millipore $(0,22 \mu \mathrm{m})$ e mantidos a $-20^{\circ} \mathrm{C}$ até a utilização.

Poços de $5,0 \mathrm{~mm}$ de diâmetro foram feitos no ágar Müeller-Hinton previamente semeado com as bactérias indicadoras na concentração de $1,5 \times 10^{8}$ UFC $/ \mathrm{mL}$. A cada poço foram acrescidos $30 \mu \mathrm{L}$ dos extratos obtidos a partir dos micro-organismos endofíticos e as placas foram incubadas por 24 horas a $30^{\circ} \mathrm{C}$. Após este tempo, o diâmetro das zonas de inibição de crescimento foram 
mensurados. O controle negativo consistiu um uma alíquota de $30 \mu \mathrm{L}$ de extrato obtido a partir do meio sólido de Kado isento de crescimento. Foram avaliadas as atividades antimicrobianas frente às cepas-padrão Staphylococcus aureus ATCC 25923 e Escherichia coli ATCC 25922.

\section{Análise estatística}

Os dados obtidos a partir dos testes in vitro, realizados em triplicata, foram submetidos a análise de variância (ANOVA), e as médias foram comparadas através do teste de Scott-Knott, a $5 \%$ de significância no software SISVAR® versão 5.3 (FERREIRA, 2011).

\section{RESULTADOS E DISCUSSÃO}

Foram isolados nove diferentes morfotipos bacterianos de folhas de Gossypium hirsutum L., os quais foram nomeados de "AL" seguido de numeração. Desse total, $77,7 \%$ dos isolados apresentavam alguma das atividades avaliadas. Um número de isolado semelhante foi encontrado por Romero et al. (2015), que ao estudarem endofíticos de tomateiro conseguiram isolar 10 micro-organismos utilizando meios de cultivo não seletivos. Esses autores também observaram a versatilidade dos micro-organismos isolados em produzir diversas auxinas e metabólitos com potencial para biocontrole.

Durante a interação entre os endofíticos e os vegetais ocorre a produção de diversos metabólitos responsáveis pela adaptação dos micro-organismos ao nicho em que habitam no hospedeiro. Esses metabólitos têm papel na promoção do crescimento vegetal, defesa contra patógenos, além de serem importantes mecanismos de comunicação entre os micro-organismos e o vegetal. Ademais, os endofíticos contribuem para a produção de metabólitos nos vegetais, sobretudo de antimicrobianos em plantas de uso medicinal. Sob esse âmbito, esses microorganismos constituem-se em importante e promissora fonte de prospecção de substâncias bioativas (REINHOLD-HUREK; HUREK, 2011; BRADER et al., 2014).

A geração de AIA foi observada em $77,7 \%$ dos isolados avaliados (Tabela 1). A produção dessa auxina é uma característica comum em bactérias endofíticas e tem sido observada em diversas espécies vegetais tais como milho (SILVA et al., 2016), batata (OGATA-GUTIÉRREZ et al., 2016) e diversas plantas medicinais (KHAN et al., 2017). Embora os endofíticos sejam capazes de produzir um grande número de fitohormônios, as auxinas e, em especial, o ácido-3-indol ácetico (AIA) são os mais comumente gerados. Esses compostos apresentam papel direto no crescimento vegetal por controlarem diversos estágios do crescimento das plantas, dentre os quais destacam-se: divisão e alongamento celular, diferenciação de tecidos e aumento apical do vegetal (GOSWAMI et al., 2015).

O fósforo é um dos nutrientes mais importantes para o vegetal e está envolvido em diversos processos celulares básicos como a fotossíntese e a divisão celular. Entretanto, grande parte do fósforo no solo está na forma insolúvel, sendo um dos grandes limitantes da agricultura atual. Os ânions fosfato $\left(\mathrm{H}_{2} \mathrm{PO}^{4-} ; \mathrm{HPO}_{4}^{-2}\right)$ são extremamente reativos e formam complexos com diversos metais no solo tais como o cálcio, ferro e alumínio. Esse complexo torna os compostos insolúveis e indisponíveis ao vegetal. Os micro-organismos solubilizadores são aqueles capazes de converter as formas insolúveis do fosfato em íons solúveis e disponíveis ao vegetal (LIU et al., 2016; MONDAL et al., 2016).

Embora os endofíticos encontrados nesse estudo apresentem potencial na solubilização de fosfato, Rodrigues et al. (2016) destacam que para que a 
solubilização aconteça, os micro-organismos devem estar próximos a fonte de fósforo, haja vista que a solubilização de fosfato envolve muitas vezes a liberação de ácidos sob a fonte de fosfato. Dessa forma, é necessário avaliar posteriormente a capacidade desses endofíticos em habitar a região de solo aderida as raízes (rizosfera).

A habilidade de solubilizar fosfato esteve presente em $66,6 \%$ dos isolados, com IS variando entre 1,4 e 4 (Tabela 1). Dois isolados, AL8 e AL9 exibiram valores elevados de IS, embora fossem estatisticamente distintos. De acordo com a classificação proposta por Silva filho e Vidor (2000), IS abaixo de 2 é considerado baixo, entre 2 e 3, médio, e acima de 3, alto. O presente estudo encontrou um maior número de solubilizadores em comparação a prospecção realizada por PerezRosales et al. (2017), que observaram 55,44\% de endofíticos de raízes de jojoba solubilizadores do ânion e o estudo conduzido por Kruasuawan e Thamchaipenet (2016) que encontraram um percentual de 12,02\% de endofíticos de cana-de-açúcar com capacidade solubilizadora.

A fixação de nitrogênio foi observada em $55,5 \%$ dos isolados (Tabela 1 ). Diversos estudos têm se proposto a isolar micro-organismos fixadores de nitrogênio de plantas de interesse agronômico como o arroz (SEV et al., 2016), a cana-deaçúcar (BENEDUZI et al., 2013) e de plantas medicinais (DEVI et al., 2017). A fixação biológica de nitrogênio é a característica mais desejável dentre as associadas a uma bactéria promotora do crescimento vegetal. O nitrogênio participa de diversos processos celulares importantes e sua forma mais abundante na natureza, o nitrogênio molecular $\left(\mathrm{N}_{2}\right)$ é indisponível aos vegetais. Micro-organismos fixadores de nitrogênio são aqueles capazes de converter $\mathrm{N}_{2}$ em amônia e nitratos, formas absorvíveis pelo vegetal. Devido a carência de compostos nitrogenados no solo é necessário grande aporte de nitrogênio inorgânico para suplementação de lavouras. Dessa maneira, bactérias que apresentem fixação do mesmo, especialmente aquelas que também produzem AIA ou solubilizam fosfato constituem-se como promissores bioinoculantes (SANTI et al., 2013; AHEMAD; KIBRET, 2014).

TABELA 1: Fatores de promoção do crescimento vegetal produzidos por bactérias endofíticas de folha isoladas de algodão (Gossypium hirsutum L.).

\begin{tabular}{cccc}
\hline Isolado & Produção de AIA & $I^{*}$ & Fixação de nitrogênio \\
\hline AL1 & + & 0,0 & - \\
AL2 & + & $2,0^{\mathrm{a}}$ & + \\
AL3 & + & $2,4^{\mathrm{a}}$ & - \\
AL4 & - & 0,0 & - \\
AL5 & - & 0,0 & - \\
AL6 & + & $1,6^{\mathrm{b}}$ & + \\
AL7 & + & $1,4^{\mathrm{b}}$ & + \\
AL8 & + & $3,3^{\mathrm{c}}$ & + \\
AL9 & + & $4,0^{\mathrm{d}}$ & + \\
\hline
\end{tabular}

IS*: Índice de Solubilização. Média de três repetições do IS. As médias que apresentam letras subscritas iguais não diferem entre si (teste de Scott-Knott, $\mathrm{p}<0,05)$.

A produção de lipases e esterases foi observada somente para o isolado AL1. Por sua vez, a atividade pectinolítica foi confirmada para os isolados AL1 e 
AL8. Nenhum isolado foi capaz de degradar as três fontes celulolíticas avaliadas (Tabela 2). Embora o número de isolados produtores de enzimas extracelulares tenha sido menor que o observado por Specian et al. (2016), que isolaram endofíticos de folha de acerola, observaram que os índices enzimáticos do atual trabalho para a pectinase eram maiores que o dos referidos autores. As pectinases exibem especial aplicação na indústria alimentícia, pois facilita o processamento da mistura das frutas ou vegetais para a geração do suco, uma vez que há redução da viscosidade do polissacarídeo devido à ação enzimática, reduzindo muito os custos de produção (KHAN et al., 2013). Os morfotipos AL1 e AL8 serão submetidos a futuros ensaios para avaliar as melhores condições de geração e rendimento das enzimas para uma possível caracterização futura da mesma.

Essas enzimas extracelulares têm sido documentadas em endofíticos de diferentes fontes e estão relacionadas a colonização dos tecidos vegetais. A liberação dessas enzimas permite a degradação da parece celular vegetal e a potencial colonização dos espaços inter e intracelulares. Essas proteínas ainda participam ativamente na defesa contra patógenos (HAQUE et al., 2015). Além de seu papel na interação entre os vegetais e os micro-organismos, apresentam importantes aplicações biotecnológicas nas áreas alimentícia, têxtil, química, agronômica e médica (DUMORNÉ et al., 2017; FELESTRINO et al., 2017; MADHU; CHAKRABORTY, 2017).

TABELA 2: Valores de índices enzimáticos (IE) obtidos na avaliação qualitativa da produção de enzimas extracelulares pelas bactérias isoladas de algodão (Gossypium hirsutum L.).

\begin{tabular}{ccccc}
\hline Isolado & Lipase & Esterase & Pectinase & Celulases \\
\hline AL1 & $1,2^{\mathrm{a}}$ & $1,2^{\mathrm{a}}$ & $4,28^{\mathrm{a}}$ & $0,0^{\mathrm{a}}$ \\
AL2 & $0,0^{\mathrm{b}}$ & $0,0^{\mathrm{b}}$ & $0,0^{\mathrm{c}}$ & $0,0^{\mathrm{a}}$ \\
AL3 & $0,0^{\mathrm{b}}$ & $0,0^{\mathrm{b}}$ & $0,0^{\mathrm{c}}$ & $0,0^{\mathrm{a}}$ \\
AL4 & $0,0^{\mathrm{b}}$ & $0,0^{\mathrm{b}}$ & $0,0^{\mathrm{c}}$ & $0,0^{\mathrm{a}}$ \\
AL5 & $0,0^{\mathrm{b}}$ & $0,0^{\mathrm{b}}$ & $0,0^{\mathrm{c}}$ & $0,0^{\mathrm{a}}$ \\
AL6 & $0,0^{\mathrm{b}}$ & $0,0^{\mathrm{b}}$ & $0,0^{\mathrm{c}}$ & $0,0^{\mathrm{a}}$ \\
AL7 & $0,0^{\mathrm{b}}$ & $0,0^{\mathrm{b}}$ & $0,0^{\mathrm{c}}$ & $0,0^{\mathrm{a}}$ \\
AL8 & $0,0^{\mathrm{b}}$ & $0,0^{\mathrm{b}}$ & $2,3^{\mathrm{b}}$ & $0,0^{\mathrm{a}}$ \\
AL9 & $0,0^{\mathrm{b}}$ & $0,0^{\mathrm{b}}$ & $0,0^{\mathrm{c}}$ & $0,0^{\mathrm{a}}$ \\
\hline
\end{tabular}

Média de três repetições do IE. As médias que apresentam letras iguais, não diferem entre si (teste de Scott-Knott, $p<0,05$ ).

O isolado $A L 1$ foi o único a apresentar antagonismo frente a cepa de $S$. aureus avaliada, ao passo que nenhum dos isolados foi capaz de inibir a cepa de $E$. coli testada. O presente estudo está em concordância com os estudos conduzidos por Barbosa et al. (2015) e Doley e Jha (2016), que ao avaliarem endofíticos de plantas com usos medicinais encontraram micro-organismos capazes de inibir o crescimento de cepas patogênicas do gênero Staphylococcus.

Alguns endofíticos apresentam a capacidade de excretar substâncias com ação antimicrobiana, esses compostos podem consistir em sinalizadores importantes no mecanismo de simbiose com a planta ou apenas uma forma de competir com os demais micro-organismos habitantes daquele mesmo nicho ecológico (EL-DEEB et al., 2013). Há diversos compostos antimicrobianos primariamente associados a vegetais que foram reportados recentemente como compostos produzidos por 
endofíticos. A cumarina extraída da erva Crotalaria pallida foi encontrada nos extratos dos endofíticos Alternaria spp. e Aspergillus flavus, ressaltando a importância desses organismos na produção de metabólitos secundários dos vegetais (REHMAN, 2016). Independentemente dos resultados verificados nesses testes, os morfotipos isolados também serão testados quanto à sua capacidade de antagonizar o crescimento de fungos fitopatogênicos modelos, uma vez que é fundamentalmente vital essa avaliação sob a visão de emprego agrícola dessas bactérias no controle biológico.

\section{CONCLUSÃO}

As folhas de algodão demonstraram ser um ambiente factível para a prospecção de bactérias com as mais diversas aplicações biotecnológicas. Destacam-se os isolados AL8 e AL9 quanto a possível aplicação como microorganismos promotores do crescimento vegetal tanto do algodão, como de outros vegetais de interesse agronômico. Já o isolado AL1 destacou-se na produção de substâncias plausível de aplicação industrial e médica. Estudos futuros fazem-se necessários para identificar os micro-organismos, investigar quantitativamente a produção de auxinas e a solubilização do fosfato, assim como abranger o painel de cepas indicadoras, incluindo fitopatógenos, e a caracterização dos compostos antimicrobianos e as condições para melhor produção das enzimas.

\section{REFERÊNCIAS}

AHEMAD, M.; KIBRET, M. Mechanisms and applications of plant growth promoting rhizobacteria: current perspective. Journal of King Saud University-Science, v. 26, n. 1, p. 1-20, 2014. Disponível em: <http://dx.doi.org/10.1016/j.jksus.2013.05.001>. doi: 10.1016/j.jksus.2013.05.001

ARAÚJO, L.W.; LIMA, A.O.S.; AZEVEDO, J.L.; MARCON, J.; SOBRAL, J.K.; LACAVA, P. T. Manual: isolamento de microrganismos endofíticos. 1 ed. Piracicaba: CALQ, 2002. 86 p.

BARBOSA, E. C.; CARRRIM, A. J. I.; OLIVEIRA, B. F. R.; RIBEIRO, I. D. A., VIEIRA, J. D. G. Isolamento, identificação e avaliação das atividades enzimática e antibacteriana de micro-organismos endofíticos de Hyptis suaveolens (L.) Poit. Enciclopédia Biosfera, v. 11, n. 22, p. 3036-3055, 2015. Disponível em: <http://dx.doi.org/10.18677/Enciclopedia_Biosfera_2015_021>. doi: 10.18677/Enciclopedia_Biosfera_2015_021

BENEDUZI, A.; MOREIRA, F.; COSTA, P. B.; VARGAS, L. K.; LISBOA, B. B.; FAVRETO, R.; BALDANI, J. I.; PASSAGLIA, L. M. P. Diversity and plant growth promoting evaluation abilities of bacteria isolated from sugarcane cultivated in the South of Brazil. Applied Soil Ecology, v. 63, p. 94-104, 2013. Disponível em: <http://dx.doi.org/10.1016/j.apsoil.2012.08.010>. doi: 10.1016/j.apsoil.2012.08.010

BRADER, G.; COMPANT, B. M.; TROGNITZ, F.; SESSITSCH, A. Metabolic potential of endophytic bacteria. Current Opinion in Biotechnology, v. 27, n. 6, p. 30-37, 2014. Disponível em: <http://dx.doi.org/10.1016/j.copbio.2013.09.012>. doi: 10.1016/j.copbio.2013.09.012 
CATTELAN, A. J. Métodos quantitativos para determinação de características bioquímicas e fisiológicas associadas com bactérias promotoras de crescimento vegetal. Londrina: Embrapa Soja, 1999. 14 p.

CIANCHETTA, A. N.; DAVIS, R. M. Fusarium wilt of cotton: management strategies. Crop Protection, v. 73, n. 7, p. 40-44, 2015. Disponível em: <http://dx.doi.org/10.1016/j.cropro.2015.01.014>. doi: 10.1016/j.cropro.2015.01.014

COSTA, M. G. C.; SCHERWINSKI-PEREIRA, J. E.; OTONI, W. C. Importância das contaminações e dos microrganismos endêmicos na cultura de células, tecidos e órgãos de plantas. In: SCHERWINSKI-PEREIRA, J. E. Contaminações microbianas na cultura de células, tecidos e órgãos de plantas. Brasília: Embrapa Informação Tecnológica, 2010.

DEVI, K. A.; PANDEY, P.; SHARMA, G. D. Plant growth-promoting endophyte Serratia marcescens AL2-16 enhances the growth of Achyranthes aspera L., a medicinal plant. HAYATI Journal of Biosciences, n. 1, p. 1-8, 2017. Disponível em: <http://dx.doi.org/10.1016/j.hjb.2016.12.006>. doi: 10.1016/j.hjb.2016.12.006

DOLEY, P.; JHA, D. K. Antimicrobial activity of bacterial endophytes from medicinal endemic plant Garcinia lancifolia Roxb. Annals of Plant Sciences, v. 4, n. 12, p. 1243-1247, $2016 . \quad$ Disponível em: <http://annalsofplantsciences.com/index.php/aps/article/view/217/186>

DUMORNÉ, K.; CÓRDOVA, D. C.; ASTORGA-ELÓ, M.; RENGANATHAN, P. Extremozymes: A Potential Source for Industrial Applications. Journal of Microbiology and Biotechnology, v. 26, n. 10, p. 1-20, 2017. Disponível em: <http://dx.doi.org/10.4014/jmb.1611.11006>. doi: 10.4014/jmb.1611.11006

EL-DEEB, B.; FAYEZ, K.; GHERBAWY, Y. Isolation and characterization of endophytic bacteria from Plectranthus tenuiflorus medicinal plant in Saudi Arabia desert and their antimicrobial activities. Journal of Plant Interactions, v. 8, n. 1, p. 56-64, 2013. Disponível em: <http://dx.doi.org/10.1080/17429145.2012.680077>. doi: $10.1080 / 17429145.2012 .680077$

FELESTRINO, E. B.; SANTIAGO, I. F.; FREITAS, L. D.; ROSA, L. H.; RIBEIRO, S. P.; MOREIRA, L. M. Plant growth promoting bacteria associated with Langsdorffia hypogaea-rhizosphere-host biological interface: a neglected model of bacterial prospection. Frontiers in Microbiology, v. 8, n. 2, p. 1-15, 2017. Disponível em: <http://dx.doi.org/10.3389/fmicb.2017.00172>. doi: 10.3389/fmicb.2017.00172

FERREIRA, D. F. Sisvar: a computer statistical analysis system. Ciência e Agrotecnologia (UFLA), v. 35, n. 6, p. 1039-1042, 2011. Disponível em: <http://dx.doi.org/10.1590/S1413-70542011000600001>. doi: 10.1590/S141370542011000600001

GORDON, S. A.; WEBER, R. P. Colorimetric estimation of indoleacetic acid. Plant Physiology, v. 26, n. 1, p. 192-195, 1951. Disponível em: <https://www.ncbi.nlm.nih.gov/pmc/articles/PMC437633/> 
GOSWAMI, D.; THAKKER, J. N.; DHANDHUKIA, P. C. Simultaneous detection and quantification of indole-3-acetic acid (IAA) and indole-3-butyric acid (IBA) produced by rhizobacteria from L-tryptophan (Trp) using HPTLC. Journal of Microbiological Methods, v. 110, n. 3, p. 7-14, 2015. Disponível em: <http://dx.doi.org/10.1016/j.mimet.2015.01.001>. doi: 10.1016/j.mimet.2015.01.001

HAQUE, M. A.; LEE, J. H.; CHO, K. M. Endophytic bacterial diversity in Korean kimchi made of Chinese cabbage leaves and their antimicrobial activity against pathogens. Food Control, v. 56, n. 10, p. 24-33, 2015. Disponível em: <http://dx.doi.org/10.1016/j.foodcont.2015.03.006>.

10.1016/j.foodcont.2015.03.006

HARDOIM, P. R.; VAN OVERBEEK, L. S.; VAN ELSAS, J. D. Properties of bacterial endophytes and their proposed role in plant growth. Trends in Microbiology, v. 16, n. $10, \quad$ p. $463-471, \quad 2008 . \quad$ Disponível em: <http://dx.doi.org/10.1016/j.tim.2008.07.008>. doi: 10.1016/j.tim.2008.07.008

JOE, M. M.; DEVARA, J. S.; BENSON, A.; SA, T. Isolation of phosphate solubilizing endophytic bacteria from Phyllanthus amarus Schum \& Thonn: evaluation of plant growth promotion and antioxidant activity under salt stress. Journal of Applied Research on Medicinal and Aromatic Plants, v. 2, n. 3, p. 71-77, 2016. Disponível em: <http://dx.doi.org/10.1016/j.jarmap.2016.02.003>. doi: 10.1016/j.jarmap.2016.02.003

KADO, C. I.; HESKETT, M. G. Selective media for isolation of Agrobacterium, Corynebacterium, Erwinia, Pseudomonas and Xanthomonas. Phytopathology, v. 60, n. 6, p. 969-976, 1970. Disponível em: <http://dx.doi.org/10.1094/Phyto-60-969>. doi: $10.1094 /$ Phyto-60-969

KHAN, A. L.; GILANI, S. A.; WAQAS, M.; AL-HOSNI, K.; AL-KHIZIRI, S.; KIM, Y.; ALI, L.; KANG, S.; ASAF, S.; SHAHZAD, R.; HUSSAIN, J.; LEE, I.; AL-HARRASI, A. Endophytes from medicinal plants and their potential for producing indole acetic acid, improving seed germination and mitigating oxidative stress. Journal of Zhejiang University. Science. B, v. 18, n. 2, p. 125-137, 2017. Disponível em: < http://dx.doi.org/10.1631/jzus.B1500271>. doi: 10.1631/jzus.B1500271

KHAN, M.; NAKKEERAN, E.; UMESH-KUMAR, S. Potential application of pectinase in developing functional foods. Annual Reviews of Food Science and Technology, v. 4, p. 21-34, 2013. Disponível em: <http://dx.doi.org/ 10.1146/annurev-food030212-182525>. doi: 10.1146/annurev-food-030212-182525

KRUASUWAN, W.; THAMCHAIPENET, A. Diversity of culturable plant growthpromoting bacterial endophytes associated with sugarcane roots and their effect of growth by co-inoculation of diazotrophs and actinomycetes. Journal of Plant Growth Regulation, v. 35, n. 4, p. 1074-1087, 2016. Disponível em: < http://dx.doi.org/10.1007/s00344-016-9604-3>. doi: 10.1007/s00344-016-9604-3

LIRA-CADETE, L.; FARIAS, A. R. B.; RAMOS, A. P. S.; COSTA, D. P.; FREIRE, F. J.; KUKLINSKY-SOBRAL, J. Variabilidade genética de bactérias diazotróficas associadas a plantas de cana-de-açúcar capazes de solubilizar fosfato inorgânico. 
Bioscience Journal, Uberlândia, v. 28, n. 1, p. 122-129, 2012. Disponível em: <http://www.seer.ufu.br/index.php/biosciencejournal/article/view/13248>

LIU, M.; LIU, X.; CHENG, B.; MA, X.; LYU, X.; ZHAO, X.; JU, Y.; MIN, Z.; FANG, Y. Selection and evaluation of phosphate-solubilizing bacteria from grapevine rhizospheres for use as biofertilizers. Spanish Journal of Agricultural Research, v. 14, v. 4, p. 1-10, 2016. Disponível em: < http://dx.doi.org/10.5424/sjar/20161449714>. doi: $10.5424 / \mathrm{sjar} / 2016144-9714$

LOPEZ, D. C.; SWORD, G. A. The endophytic fungal entomopathogens Beauveria bassiana and Purpureocillium lilacinum enhance the growth of cultivated cotton (Gossypium hirsutum) and negatively affect survival of the cotton bollworm (Helicoverpa zea). Biological Control, v. 89, n. 10, p. 53-60, 2015. Disponível em: < http://dx.doi.org/10.1016/j.biocontrol.2015.03.010>.

10.1016/j.biocontrol.2015.03.010

MADHU, A; CHAKRABORTY, J. N. Developments in application of enzymes for textile processing. Journal of Cleaner Production, v. 145, n. 3, p. 114-133, 2017. Disponível em: <http://dx.doi.org/10.1016/j.jclepro.2017.01.013>. doi: 10.1016/j.jclepro.2017.01.013

MONDAL, D.; ISLAM, M.S.; HOQUE, M.F.; HOSSAIN, M. K.; ISLAM, M. K.;HOSSIN, M. S.; AHSAN, S. M. Isolation and screening of potential phosphate solubilizing bacteria (PSB) from tidal saline soils of Bangladesh. Octa Journal of Environmental Research, v. 4, n. 3, p. 198-207, 2016. Disponível em: $<$ http://sciencebeingjournal.com/sites/default/files/02_0403_MS.pdf>.

MUNJAL, V.; NADAKKAKATH, A. V.; SHEORAN, N.; KUNDU, A.; VENUGOPAL, V.; SUBAHARAN, K.; RAJAMMA, S.; EAPEN, S. J.; KUMAR, A. Genotyping and identification of broad spectrum antimicrobial volatiles in black pepper root endophytic biocontrol agent, Bacillus megaterium BP17. Biological Control, v. 92, n. 1, p. 66-76, 2016. Disponível em: <http://dx.doi.org/10.1016/j.biocontrol.2015.09.005>. doi: 10.1016/j.biocontrol.2015.09.005

NAUTIYAL, C. S. An efficient microbiological growth medium for screening phosphate solubilizing microorganisms. FEMS Microbiology Letters, v. 170, n. 1, p. 265-270, 1999. Disponível em: <http://dx.doi.org/10.1111/j.15746968.1999.tb13383.x>. doi: 10.1111/j.1574-6968.1999.tb13383.x

OGATA-GUTIÉRREZ, K.; ALVARADO, D.; CHUMPITAZ-SEGOVIA, C. Characterization of plant growth promoting rhizobacteria isolated from the rhizosphere of Peruvian highlands native crops. International Journal of Plant \& Soil Science, v. 11, n. 1, p. 1-8, 2016. Disponível em: <http://dx.doi.org/10.9734/IJPSS/2016/24573>. doi: 10.9734/IJPSS/2016/24573

PEREIRA, S. I. A.; MONTEIRO, C.; VEGA, A. L.; CASTRO. P. M. L. Endophytic culturable bacteria colonizing Lavandula dentata L. plants: isolation, characterization and evaluation of their plant growth-promoting activities. Ecological Engineering, v. 87, p. $\quad 91-97,2016.2$ Disponível 
$<$ http://dx.doi.org/10.1016/j.ecoleng.2015.11.033>.

doi:

10.1016/j.ecoleng.2015.11.033

PEREZ-ROSALES, E.; ALCARAZ-MELÉNDEZ, L.; PUENTE, M. E.; VÁZQUEZJUÁREZ, R.; QUIROZ-GUZMÁN, E.; ZENTENO-SAVÍN, T.; MORALESBOJÓRQUEZ, E. Isolation and characterization of endophytic bacteria associated with roots of jojoba (Simmondsia chinensis (Link) Schneid). Current Science, v. 112, n. 2, p. 396-401, 2017. Disponível em: <http://dx.doi.org/10.18520/cs/v112/i02/396401>. doi: $10.18520 / \mathrm{cs} / \mathrm{v} 112 / \mathrm{i} 02 / 396-401$

REHMAN, S. Endophytes: the producers of important functional metabolites. International Journal of Current Microbiology and Applied Science, v. 5, n. 5, p. 377-391, 2016. Disponível em: <http://dx.doi.org/10.20546/ijcmas.2016.505.039>. doi: 10.20546/ijcmas.2016.505.039

REINHOLD-HUREK, B.; HUREK, T. Living inside plants: bacterial endophytes. Current Opinion in Plant Biology, v. 14, n. 4, p. 435-443, 2011. Disponível em: <http://dx.doi.org/10.1016/j.pbi.2011.04.004>. doi: 10.1016/j.pbi.2011.04.004

RENNIE, R. J. A single medium for the isolation of acetylene-reducing (dinitrogenfixing) bacteria from soils. Canadian Journal of Microbiology, v. 27, n. 1, p. 8-14, 1981. Disponível em: <https://www.ncbi.nlm.nih.gov/pubmed/7214234>

RODRIGUES, A. A.; FORZANI, M. V.; SOARES, R. S.; SIBOV, S. T.; VIEIRA, J. D. G. Isolation and selection of plant growth-promoting bacteria associated with sugarcane. Pesquisa Agropecuária Tropical, v. 46, n. 2, p. 149-158, 2016. Disponível em: <http://dx.doi.org/10.1590/1983-40632016v4639526>. doi: 10.1590/1983-40632016v4639526

ROMERO, F. M.; MARINA, M.; PIECKENSTAIN, F. L. Novel components of leaf bacterial communities of field-grown tomato plants and their potential for plant growth promotion and biocontrol of tomato diseases. Research in Microbiology, v. 16, n. 3, p. 222-233, 2015. Disponível em: <http://dx.doi.org/10.1016/j.resmic.2015.11.001>. doi: 10.1016/j.resmic.2015.11.001

ROMEIRO, R.S.Constatação da produção de bacteriocinas por isolamentos de bactérias fitopatogênicas. In. ROMEIRO, R.S.(ed) Métodos em bacteriologia de plantas. Viçosa: editora UFV, p.163-172, 1989.

SANTI, C.; BOGUSZ, D.; FRANCHE, C. Biological nitrogen fixation in non-legume plants. Annals of Botany, v. 111, n. 5, p. 743-767, 2013. Disponível em: <http://dx.doi.org/10.1093/aob/mct048>. doi: 10.1093/aob/mct048

SANTOS, T. T.; VARAVALLO, M. A. Aplicação de microrganismos endofíticos na agricultura e na produção de substâncias de interesse econômico. Semina: Ciências Biológicas e da Saúde, v. 32, n. 2, p. 199-212, 2011. Disponível em: <http://dx.doi.org/10.5433/1679-0367.2011v32n2p199>. doi: 10.5433/16790367.2011v32n2p199 
SEV, T. M.; KHAI, A. A.; AUNG, A.; YU, S. S. Evaluation of endophytic bacteria from some rice varieties for plant growth promoting activities. Journal of Scientific and Innovative Research, v. 5, n. 4, p. 144-148, 2016. Disponível em: <http://dx.doi.org/10.13140/RG.2.2.35453.36322>.doi: 0.13140/RG.2.2.35453.36322

SIERRA, G. A. A simple method for the detection of lipolytic activity of microorganisms and some observations on the influence of the contact between cells and fatty substrates. Antonie van Leeuwenhoek, v. 23, n. 1, p. 15-22, 1975. Disponível em: <http://dx.doi.org/10.1007/BF02545855>. doi: 10.1007/BF02545855

SILVA FILHO, G. N.; VIDOR, C. Solubilização de fosfatos por microrganismos na presença de fontes de carbono. Revista Brasileira de Ciência do Solo, Viçosa, v. 24, n. 2, p. 311-319, 2000. Disponível em: <http://www.scielo.br/pdf/rbcs/v24n2/08.pdf>.

SILVA, K.; PERIN, P.; GOMES, M.L.; BARAÚNA, A. C.; PEREIRA, G. M. D.; MOSQUEIRA, C. A.; COSTA, I. B.; O'HARA, G.; ZILLI, J. E. Diversity and capacity to promote maize growth of bacteria isolated from the Amazon region. Acta Amazonica, v. 46, n. 2, p. 111-118, 2016. Disponível em: <http://dx.doi.org/10.1590/1809-4392201502502>. doi: 10.1590/18094392201502502

SPECIAN, V.; COSTA, A. T.; FELBER, A. C.; POLONIO, J. C.; AZEVEDO, J. L.; PAMPHILE, J. A. Molecular phylogeny and biotechnological potential of bacterial endophytes associated with Malpighia emarginata. Genetics and Molecular Research: GMR, v. 15, n. 2, 2016. Disponível em: <http://dx.doi.org/10.4238/gmr.15027777>. doi: 10.4238/gmr.15027777

STAMFORD, T. L. M.; ARAÚJO, J. M.; STAMFORD, N. P. Atividade enzimática de microorganismos isolados de jacatupé (Pachyrhizus erosus L. Urban). Ciência e Tecnologia de Alimentos, v. 18, n. 4, p. 382-385, 1998. Disponível em: <http://dx.doi.org/10.1590/S0101-20611998000400004>. doi: 10.1590/S010120611998000400004

WEGIER, A.; ALAVEZ, V.; PIÑERO, D. Cotton: Traditional and Modern Uses. In: LIRA, R.; CASAS, A.; BLANCAS, J. Ethnobotany of Mexico. New York: Springer, p. 439-456.2016.

WENDEL, J. F.; BRUBAKER, C. L.; SEELANAN, T. The origin and evolution of Gossypium. In:STEWART, J. M.; OOSTERHUIS, D. M.; HEITHOLT, J. J.; MAUNEY, J. R. Physiology of Cotton. Netherlands: Springer,p. 1-18.2010. 